\title{
Airborne transmission between room occupants during short-term events: Measurement and evaluation
}

\author{
Ai, Zhengtao; Hashimoto, Kaho; Melikov, Arsen Krikor
}

Published in:

Indoor Air

Link to article, DOI:

10.1111/ina.12557

Publication date:

2019

Document Version

Peer reviewed version

Link back to DTU Orbit

Citation (APA):

Ai, Z., Hashimoto, K., \& Melikov, A. K. (2019). Airborne transmission between room occupants during short-term events: Measurement and evaluation. Indoor Air, 29(4), 563-576. https://doi.org/10.1111/ina.12557

\section{General rights}

Copyright and moral rights for the publications made accessible in the public portal are retained by the authors and/or other copyright owners and it is a condition of accessing publications that users recognise and abide by the legal requirements associated with these rights.

- Users may download and print one copy of any publication from the public portal for the purpose of private study or research.

- You may not further distribute the material or use it for any profit-making activity or commercial gain

- You may freely distribute the URL identifying the publication in the public portal

If you believe that this document breaches copyright please contact us providing details, and we will remove access to the work immediately and investigate your claim 
DR. ZHENGTAO Al (Orcid ID : 0000-0003-2635-2170)

Article type : Original Article

\title{
Airborne Transmission between Room Occupants during Short-Term Events: Measurement and Evaluation
}

\author{
Z.T. Ai ${ }^{1, *}$, K. Hashimoto ${ }^{1,2}$, A.K. Melikov ${ }^{1}$ \\ ${ }^{1}$ International Centre for Indoor Environment and Energy, Department of Civil Engineering, \\ Technical University of Denmark \\ ${ }^{2}$ Department of Architecture, Faculty of Science and Engineering, Waseda University
}

*Corresponding email: zheai@byg.dtu.dk

ORCID:

Z.T. Ai: 0000-0003-2635-2170

A.K. Melikov: 0000-0003-0200-6046

\begin{abstract}
This study experimentally examines and compares the dynamics and short-term events of airborne cross infection in a full-scale room ventilated by stratum, mixing and displacement air distributions. Two breathing thermal manikins were employed to simulate a standing infected person and a standing exposed person. Four influential factors were examined, including separation distance between manikins, air change per hour, positioning of the two manikins and air distribution. Tracer gas technique was used to simulate the This article has been accepted for publication and undergone full peer review but has not been through the copyediting, typesetting, pagination and proofreading process, which may lead to differences between this version and the Version of Record. Please cite this article as doi: 10.1111/ina.12557
\end{abstract}

This article is protected by copyright. All rights reserved. 
exhaled droplet nuclei from the infected person and fast tracer gas concentration meters (FCM41) were used to monitor the concentrations. Real-time and average exposure indices were proposed to evaluate the dynamics of airborne exposure. The time-averaged exposure index depends on the duration of exposure time and can be considerably different during short-term events and under steady-state conditions. The exposure risk during short-term events may not always decrease with increasing separation distance. It changes over time and may not always increase with time. These findings imply that the control measures formulated on the basis of steady-state conditions are not necessarily appropriate for shortterm events.

Keywords: airborne transmission, indoor air quality, building ventilation, dynamics, shortterm events, concentration measurement

\section{Practical implications}

The transient characteristics of cross infection between room occupants during short-term events revealed in this study improve our understanding of airborne transmission. The obtained knowledge can contribute to improved control measures for airborne transmission during short-term events. The new exposure indices developed in this study are useful for future studies of dynamic airborne exposure.

\section{Introduction}

It has been shown that the transmission of virus-contained exhaled air in indoor environments, namely airborne transmission, is one of major person-to-person dissemination routes for a number of infectious diseases, such as tuberculosis, measles, smallpox, severe acute respiratory syndrome (SARS), chickenpox, anthrax, mumps, avian influenza and 
influenza. ${ }^{1-2}$ Enclosed indoor environments are among the most high-risk occasions for airborne transmission, given that people spend most of their time indoors and that indoor spaces are usually densely populated and less well ventilated. Knowledge of the mechanism and characteristics of airborne transmission between room occupants is thus of great importance for developing effective exposure control measures, particularly during outbreaks of infectious diseases or in highly vulnerable places.

Airborne cross-infection between an infected person and an exposed person in indoor environments takes place by direct and indirect transmission ${ }^{3}$. Direct transmission occurs when the air exhaled by the infected person is inhaled by the exposed person after entering and mixing with the breathing zone air of the exposed person. Indirect transmission occurs when the air exhaled by the infected person disperses and mixes with the room air before it reaches the breathing zone and is inhaled by the exposed person. The risk of cross infection from direct transmission can be influenced by a number of different parameters, such as air distribution, distance between the persons, positions and orientations of the persons, breathing mode, activity level and occupant movement, while the risk of cross infection from indirect transmission is influenced mainly by the volume of the occupied space and the supply air flow rate. ${ }^{4}$ Past studies have examined these parameters and some important findings have been reported. The transport of exhaled droplet nuclei from an infected person to an exposed person in the indoor environment is governed by a complex interaction of various airflows, including breathing flow, human body boundary layer flow ${ }^{5}$ and ventilation flow. The distance between persons determines which will be the dominant air flow. ${ }^{6}$ For short distances (e.g., $\leq 0.5 \mathrm{~m}$ ), the human microenvironment, including the interaction between breathing flows, plays a key role in determining the risk of cross-infection; for longer distances the ventilation flow is more important. In general, the risk of cross-infection

This article is protected by copyright. All rights reserved. 
sharply decreases with as the distance between occupants increases, until the distance reaches approximately $0.8-1.5 \mathrm{~m}^{7-13}$ and the risk has become close to what it would be under wellmixed conditions. As the exhaled flows are highly directional, the position and orientation of the occupants are important factors in determining the risk of cross-infection, especially over short distances. Under most conditions, face-to-face orientation leads to the highest risk and face-to-back the lowest risk. ${ }^{10,14-15}$ A knowledge of the influence of these parameters is fundamental for formulating effective control measures.

In the engineering discipline of indoor air, our understanding of the characteristics of exhaled droplet nuclei and the evaluation of the risk of cross-infection have been gained either in experimental studies in test rooms or in numerical studies using Computational Fluid Dynamics (CFD) simulations. Accurate sampling of the concentration at important locations, such as the air inhaled by the exposed thermal manikin and the ventilation exhaust, is an essential element of the research methods used in these studies. Tracer gas has been widely used to simulate the transfer of exhaled droplet nuclei ${ }^{3,9,10,13,15,16}$ and the rationale of this approach has been discussed extensively. ${ }^{17}$ However, most tracer gas instruments, including the widely used photoacoustic gas monitor INNOVA, have a sampling time of the order of 10-60 second, which is much longer than the period of inhalation or exhalation (which are of the order of 1 second). Aerosol generators have been increasingly used to provide a more accurate simulation of the transfer of exhaled droplet nuclei. ${ }^{14,18-22}$ However, they are mostly used alone (i.e. not in conjunction with a manikin) and have a sampling interval of no smaller than $1 \mathrm{~s} .{ }^{14,21,22} \mathrm{CFD}$ techniques are capable of performing high time-resolution sampling of the concentration. However, past CFD studies of airborne transmission were limited to the use of steady-state Reynolds Average Navier Stokes (RANS) turbulence models. ${ }^{23-24}$ In general, these low time-resolution research techniques have been applied under steady-state 
conditions. The dynamic process of the transport of exhaled droplet nuclei is still awaiting exploration.

Apart from steady-state conditions, the dynamic process of the transport of exhaled droplet nuclei can also be worth investigation, for the following reasons. First, human breathing activities are highly dynamic processes, consisting of exhalation, inhalation and a break, ${ }^{25}$ and the infectious droplet nuclei are released only during the exhalation phase. The dynamics of airborne transmission between occupants depends on the interaction between ventilation flow, convective boundary layer and thermal plume of the body, and breathing flows. Second, under certain conditions, the risk of cross-infection is determined by the exposed dose, including both concentration and duration of exposure. Accurate and fast sampling of the concentration over time (since the start of the event) is especially important for a reliable evaluation of the exposure risk during short-term events. Typical examples of such short-term events include a short meeting and a consultation with a physician. However, it has to be made clear that there could be two types of short-term events in real life. One has a steady-state background concentration; namely the infected person has been in the space for a sufficiently long time. Another has a building-up background concentration; namely the infected person has just entered the space. The present study focuses only on the second type. Third, in order to evaluate the risk of cross-infection and formulate cost effective intervention measures for a certain type of pathogen, it is important to compare the timescale of accumulating a dose and the survival time. ${ }^{4,26}$ This comparison can be made only on the basis of dynamic measurements. In general, to improve the understanding of airborne transmission and thus to formulate more accurate control measures, especially for short-term events, it is necessary to investigate the dynamic transport process of exhaled droplet nuclei between occupants.

This article is protected by copyright. All rights reserved. 
The objective of this study is to investigate the dynamics and short-term events of airborne transmission between persons. Experiments were conducted in a test room and two breathing thermal manikins were used to simulate a standing infected person and a standing exposed person, respectively. Four important influential parameters were varied systematically: the separation distance between the manikins (from 0.35 to $1.5 \mathrm{~m}$ ); air change rate per hour $\left(2 \mathrm{~h}^{-1}\right.$ and $\left.6 \mathrm{~h}^{-1}\right)$; orientation of the two manikins (face-to-face and face-to-back); and air distribution system (stratum, mixing and displacement). Tracer gas technique was used to simulate the exhaled droplet nuclei from the infected person and fast concentration meters (FCM41, see section 2.3 for details) were used to monitor the concentrations. Particular attention was paid to accurate measurement, reliable evaluation of dynamic airborne transmission, and to increasing our understanding of the general characteristics and special aspects of short-term events that are different from those under steady-state conditions. The findings of this study are expected to contribute to improved control measures for airborne transmission of infection indoors.

\section{Methods}

\subsection{Experimental setup}

\subsubsection{Test room}

The experiments were conducted in a full-scale test room with dimensions of $4.4 \mathrm{~m} \times 4.7$ $\mathrm{m} \times 2.6 \mathrm{~m}$ (see Figure 1 (a)-(c)). The walls of the room were made of insulated chipboard, except that one of the walls was made of thick single-layer glazing. The room was built in a large laboratory hall, where the air temperature was controlled by a separate ventilation system. In this study, the air temperature in the laboratory hall was controlled to be the same as that inside the room, to improve the stability of the air temperature inside the room. Six fluorescent light fixtures of $6 \mathrm{~W}$ each were mounted on the ceiling to provide lighting. Two

This article is protected by copyright. All rights reserved. 
breathing thermal manikins were used to simulate one infected person and one exposed person. The sensible heat power of each manikin was $80 \mathrm{~W}$, so the total heat load generated in the test room was $9.5 \mathrm{~W} / \mathrm{m}^{2}$.
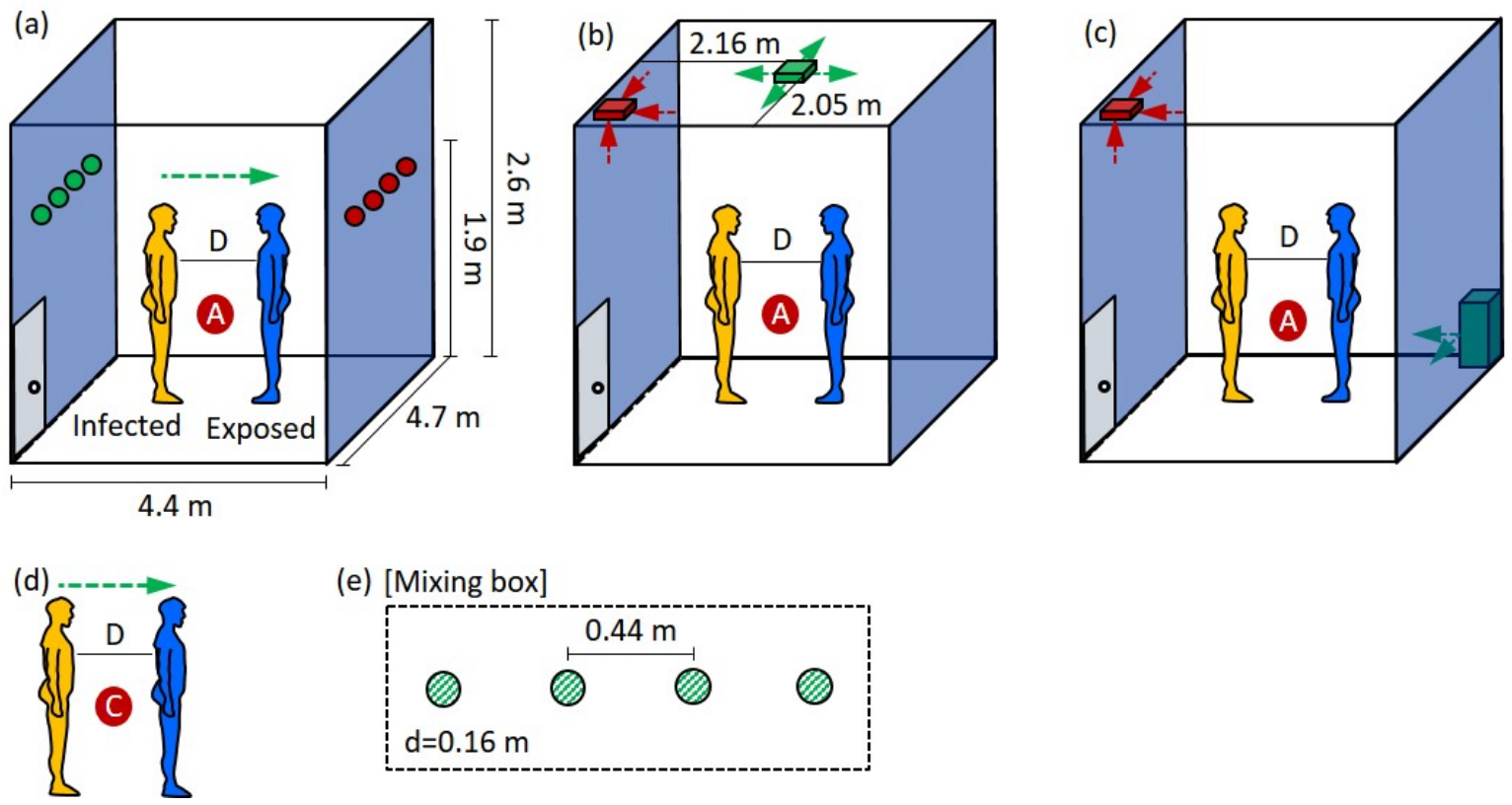

(e) [Mixing box]

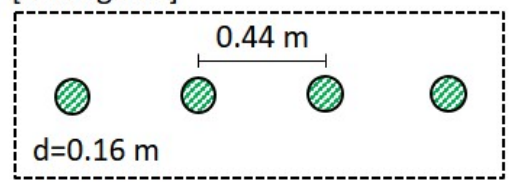

Figure 1 Schematic view of the full-scale test room mounted with stratum air distribution (SV) (a), mixing air distribution (MV) (b) and displacement air distribution (DV) (c); the face-to-face positioning (a)-(c) and the face-to-back positioning (d); and the mixing box and diffusers of the stratum air distribution (e); the separation distance ' $\mathrm{D}$ ' between occupants refers to the mouth-to-mouth distance.

\subsubsection{Air distribution}

Experiments were performed with stratum, mixing and displacement air distribution. A schematic view of the test room and the three air distribution methods are provided in Figure 1 (a)-(c). The stratum air distribution (SV) was proposed by Lin et al., ${ }^{27}$ and was found to be a suitable energy-efficient way of maintaining the indoor thermal environment in small-tomedium sized spaces. ${ }^{27}$ For SV, four round diffusers with perforated face plates were used for both the supply and the exhaust purposes, which were mounted on the side walls and at a height of $1.9 \mathrm{~m}$. For the mixing air distribution (MV), a square supply diffuser with a 
perforated face plate was installed at the centre of the ceiling with an exhaust diffuser in the corner of the ceiling. To achieve displacement ventilation (DV), a semicircular perforated diffuser was installed on the floor in the corner of the room and a square exhaust intake in the corner of the ceiling. During the experiments, $100 \%$ outdoor air was supplied to the room.

\subsubsection{Breathing thermal manikins}

Two breathing thermal manikins with the accurate body shape and size of an average adult woman of $1.7 \mathrm{~m}$ in height were used. The manikin simulating an infected standing person (referred to below as the source manikin) consisted of 17 separately heated body segments and the manikin simulating an exposed standing person (referred to below as the exposed manikin) had 23 such segments. The temperature and heat power of the body segments were controlled separately by a computer program. In this experiment, the surface temperature of the standing manikins was controlled to be close to the skin temperature of a person in a state of thermal comfort. The manikins were wore a short-haired wig, T-shirt, trousers, underwear, ankle-length light socks and light shoes, which together provided 0.5 Clo of thermal insulation. The thermal manikins were able to realistically establish the free convection flow around and thermal plume above a human body.

Each manikin was connected to a set of artificial lungs ${ }^{28}$ to simulate human breathing. The pulmonary ventilation rate was $6.0 \mathrm{~L} / \mathrm{min}$ and the breathing frequency was 10.0 times/min. Each breathing cycle consisted of $2.5 \mathrm{~s}$ inhalation, $2.5 \mathrm{~s}$ exhalation, and $1.0 \mathrm{~s}$ break. The breathing mode of the source manikin was inhalation through the nose and exhalation through the mouth and that of the exposed manikin was inhalation through the mouth and exhalation through the nose. This combination of breathing modes had been found to be the

worst condition for cross infection in most circumstances. ${ }^{6}$ Note that the breathing phase of

This article is protected by copyright. All rights reserved. 
the two manikins was not controlled. The exhaled air was heated to 34.7 , without being humidified. ${ }^{29}$ The nostrils were circular openings, each with a cross-sectional area of 38.5 $\mathrm{mm}^{2}$. The mouth was an ellipsoidal opening with a cross-sectional area of $158 \mathrm{~mm}^{2}{ }^{25}$ The two jets from the nostrils were angled $45^{\circ}$ downwards from the horizontal plane and $30^{\circ}$ from each other. ${ }^{30}$

\subsection{Experimental conditions}

A real-life photo of part of the experimental setup is shown in Figure 2. In the experiments with stratum air distribution, the manikins were located on a vertical plane between the diffusers, avoiding the direct jet flows. The source manikin was located $1.1 \mathrm{~m}$ away from the wall with the diffusers, where the air speeds were less than $0.8 \mathrm{~m} / \mathrm{s}$. Apart from air distribution, a further three parameters were varied: air change per hour $(\mathrm{ACH})$, positioning of the two manikins and separation distance between the two manikins. The detailed experimental cases and conditions are summarized in Table 1. The design of these experimental conditions was based on a compromise between experimental resources and the capability to reveal the characteristics of airborne transmission during short-term events. The $\mathrm{ACH}$ values of $2 \mathrm{~h}^{-1}$ and $6 \mathrm{~h}^{-1}$ were selected to represent relatively low and high air change rates that commonly occur in office environments. Face-to-face and face-to-back positioning were selected, as they are known to be the riskiest and safest arrangements, respectively. ${ }^{10,14,16}$ The exposed manikin was moved to change the separation distance. The separation distances studied were $0.35,0.5,1.0$ and $1.5 \mathrm{~m}$. The distances $0.35 \mathrm{~m}$ and $0.5 \mathrm{~m}$ were intended to represent close conditions with direct interaction of breathing flows, and since at $1.5 \mathrm{~m}$ well-mixed conditions with negligible interaction of breathing flows was

expected, $1.0 \mathrm{~m}$ was selected to be in between. ${ }^{6}$ The room air temperature was controlled to be $24 \pm 0.5$. The relative humidity of the indoor air was not controlled but was measured to be approximately from $30 \%$ to $40 \%$ during the experiments.

This article is protected by copyright. All rights reserved. 


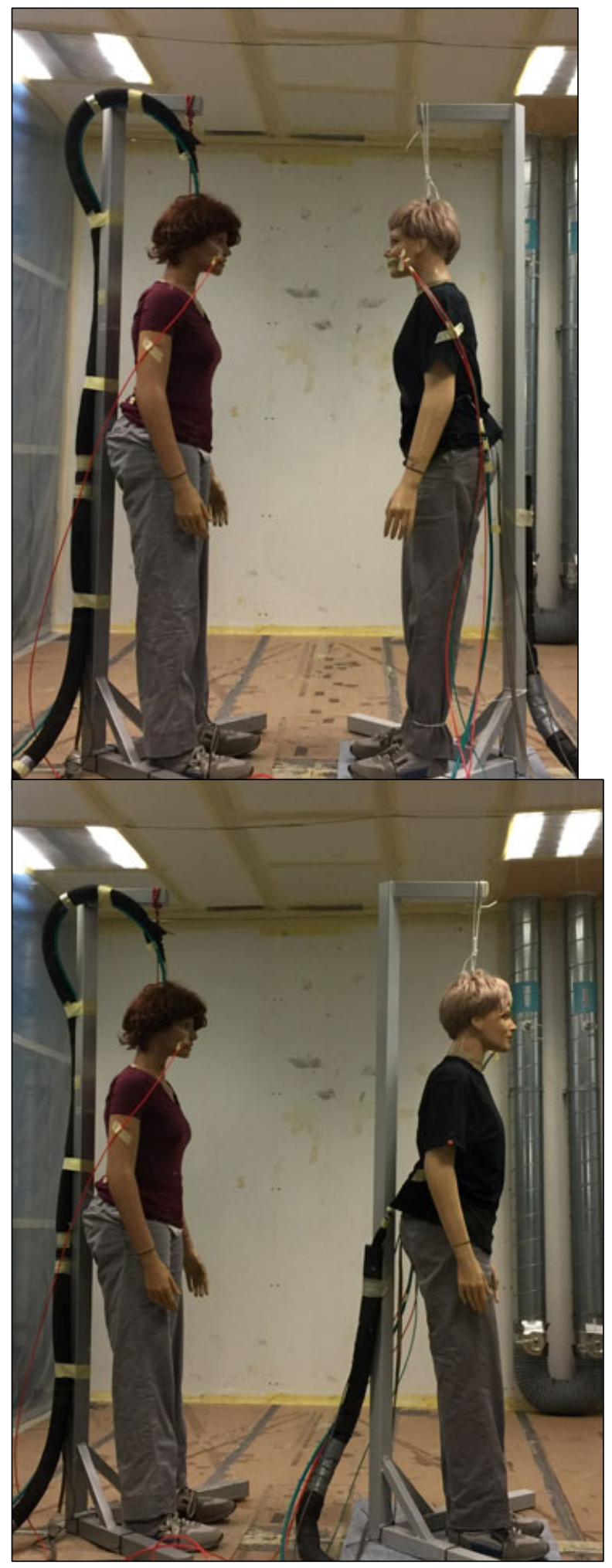

Figure 2 The real-life set-up of the face-to-face (Termed Positioning A) and face-to-back positioning (Termed Positioning $\mathrm{C}$ ), in which the left manikin simulated an infected person and the right one an exposed person; the tubes visible in the figures were used for connecting the artificial lungs and tracer gas monitors.

This article is protected by copyright. All rights reserved. 
Table 1 A list of experimental conditions.

\begin{tabular}{|c|c|c|c|c|c|}
\hline Cases & Conditions & $\begin{array}{l}\text { Air } \\
\text { distribution }\end{array}$ & $\operatorname{ACH}\left(h^{-1}\right)$ & $\begin{array}{l}\text { Positioning } \\
\text { of two } \\
\text { manikins }\end{array}$ & $\begin{array}{l}\text { Separation distance } \\
\text { D (m) }\end{array}$ \\
\hline 1 & $1-4$ & SV & 2 & $\mathrm{~A}$ & $0.35,0.5,1.0,1.5$ \\
\hline 2 & $5-8$ & SV & 2 & $\mathrm{C}$ & $0.35,0.5,1.0,1.5$ \\
\hline 3 & $9-12$ & SV & 6 & $\mathrm{~A}$ & $0.35,0.5,1.0,1.5$ \\
\hline 4 & $13-16$ & SV & 6 & $\mathrm{C}$ & $0.35,0.5,1.0,1.5$ \\
\hline 5 & $17-20$ & MV & 2 & A & $0.35,0.5,1.0,1.5$ \\
\hline 6 & $21-24$ & MV & 2 & $\mathrm{C}$ & $0.35,0.5,1.0,1.5$ \\
\hline 7 & $25-28$ & MV & 6 & A & $0.35,0.5,1.0,1.5$ \\
\hline 8 & $29-32$ & MV & 6 & $\mathrm{C}$ & $0.35,0.5,1.0,1.5$ \\
\hline 9 & $33-36$ & DV & 2 & A & $0.35,0.5,1.0,1.5$ \\
\hline 10 & $37-40$ & DV & 2 & $\mathrm{C}$ & $0.35,0.5,1.0,1.5$ \\
\hline 11 & $41-44$ & $\mathrm{DV}$ & 6 & $\mathrm{~A}$ & $0.35,0.5,1.0,1.5$ \\
\hline 12 & $45-48$ & $\mathrm{DV}$ & 6 & $\mathrm{C}$ & $0.35,0.5,1.0,1.5$ \\
\hline
\end{tabular}

\subsection{Measured parameters and instrumentation}

Tracer gas $\left(\mathrm{N}_{2} \mathrm{O}\right.$, nitrous oxide) was used to simulate the exhaled virus-laden droplet nuclei from the source manikin. It was dosed directly into the exhaled flow of the source manikin through the artificial lung. The dosing rate was $0.5 \mathrm{~L} / \mathrm{min}$, which approximates to the fraction of $\mathrm{CO}_{2}$ in the exhaled flows. The air supplied from the lungs was decreased with by same amount $(0.5 \mathrm{~L} / \mathrm{min})$ in order to maintain a constant total exhaled flow rate. In this way, the initial momentum of the exhaled flow, and thus the delivery distance of the tracer gas, a key factor influencing the exposure, was maintained. A sensitivity test shows that the dosing rate of $0.4,0.5$ and $0.6 \mathrm{~L} / \mathrm{min}$ gave very similar exposure index, when keeping the same amount of pulmonary ventilation rate. Two instruments measuring $\mathrm{N}_{2} \mathrm{O}$ concentration, a Fast Concentration Meter (FCM 41) and an INNOVA Multi-gas Sampler and Monitor (1312),

This article is protected by copyright. All rights reserved. 
were cross compared under both steady-state and dynamic conditions (see section 3.1). The FCM was an instrument that was specially developed to be fast, based on a non-dispersive infrared absorption (NDIR) method. ${ }^{31,32}$ It had a sampling rate of $4 \mathrm{~Hz}$ and a time constant of $0.8 \mathrm{~s}$, so that it was able to follow the dynamic changes in each breathing cycle. The resolution of the FCM was $1.0 \mathrm{ppm}$ and the expanded uncertainty was $\pm 20.0 \mathrm{ppm}(95 \%$ confidence level). The INNOVA instrument (up to six channels) was based on the photoacoustic principle. When 2 channels were used simultaneously, the sampling rate was $80 \mathrm{~s}$ per set of data. The expanded uncertainty of the INNOVA analyser was $3 \%$ of the reading (95\% confidence level).

Throughout the experiments, the two manikins were always breathing. Continuous tracer gas measurements were performed at the mouths of the manikins (i.e. in the exhalation of the source manikin and the inhalation of the exposed manikin) and at the exhaust outlet of the ventilation system. The location of the measuring points at each mouth was centrally placed between the lips and at a distance of $0.005 \mathrm{~m}$ from the surfaces. Tracer gas dosing started after the indoor airflow distribution reached steady-state conditions and ended 40 min after the steady-state condition of the concentration had been reached (see Section 2.4). Tracer gas sampling was conducted immediately after the start of dosing. The FCM monitors were calibrated every measuring day both before and after the measurements.

\subsection{Data analyses}

Results of single sets of measurements were adopted in this paper, except in Section 3.4, where three repeated measurements under the same condition for a few cases were analyzed. Although many repeated sets of measurements are important to observe the statistical averages and variations of the risk of cross infection during a specific short-term event, the findings obtained in Section 3.4 supports the use of single sets of measurements to reveal the

This article is protected by copyright. All rights reserved. 
different characteristics of airborne transmission during short-term events and under steadystate conditions.

The INNOVA data was used directly in further analysis. The FCM data were corrected for the time required for the $\mathrm{N}_{2} \mathrm{O}$ samples to travel in the sampling tube from the sampling location to the FCM monitors, ${ }^{31}$ and Fourier transformation was then used to provide a frequency correction of the signals. These time series of concentrations were divided into two parts, before and under steady-state conditions, in the data analysis.

For the data under steady-state conditions, time-averaged mean values were calculated. In order to obtain a time-independent mean value under steady-state conditions, a sufficient number of samples are required. For INNOVA with two channels activated, a period of 40 min provided 30 samples, which was determined to be sufficient on the basis of a sensitivity test of the influence of the number of samples on the time-averaged mean values. The sampling period of 40 min included 400 breathing cycles, during which 9600 samples were collected by the FCM monitors. It has been shown that $40 \mathrm{~min}$ is a sufficiently long time for FCM to obtain a time-independent mean value. ${ }^{33}$

In combination with these time-averaged values, the data before steady-state conditions were analysed based on the new evaluation methods of dynamic airborne transmission developed in this study (see Section 3.2.2 for details).

\section{Results and analysis}

\subsection{Measurement of dynamic concentration evolution}

In order to select a reliable method of measurement for the dynamic evolution of tracer gas concentration, the slow (INNOVA) and fast (FCM) methods were compared under two circumstances. The first comparison was to measure a relatively stable concentration under steady-state conditions, i.e. constant $\mathrm{ACH}$ and tracer gas dosing rate. The measurements were performed in the test room with the MV air distribution method (see section 2.1.1-2.1.2). The

This article is protected by copyright. All rights reserved. 
tracer gas was dosed at the geometrical centre of the test room. The sampling location was at the ventilation exhaust of the test room and for each case the sampling lasted for $40 \mathrm{~min}$. The second comparison was to measure dynamic concentration development during a short period. The experimental conditions were the same as in Case 1 and are listed in Table 1, namely airborne transmission with SV system in operation with positioning A and $\mathrm{ACH}=2$ $\mathrm{h}^{-1}$ (see Section 2.1 for details).

Figure 3 shows a comparison of time-averaged concentrations under steady-state conditions, when the concentration was controlled to be in the range from 0 to $300 \mathrm{ppm}$. There is a systematic difference in the measurements obtained by the two instruments. When the concentration was above $50 \mathrm{ppm}$, the relative deviations were more stable, ranging from $12 \%$ to $20.6 \%$, with an average of $16.5 \%$. The deviations increased up to approximately 30 $40 \%$ when the concentration was between 25 and $50 \mathrm{ppm}$ and were over $100 \%$ when the concentration was less than $25 \mathrm{ppm}$. The increased deviations are believed to have occurred for two reasons. The first is that mathematically a higher relative deviation is more likely to occur between two lower numbers. The second is that, owing to its physical principle, the FCM instrument has a slightly lower resolution at low concentration. Overall, most points fall well onto the fitted line $(y=0.88 x-5.66)$ in Figure 3. Despite the deficiency of the FCM instrument in the measurement of low concentrations, especially below $25 \mathrm{ppm}$, the comparison presented in Figure 3 generally justifies the use of FCM for measurement at relatively high concentration, given that the systematic deviations can be eliminated after normalization.

This article is protected by copyright. All rights reserved. 


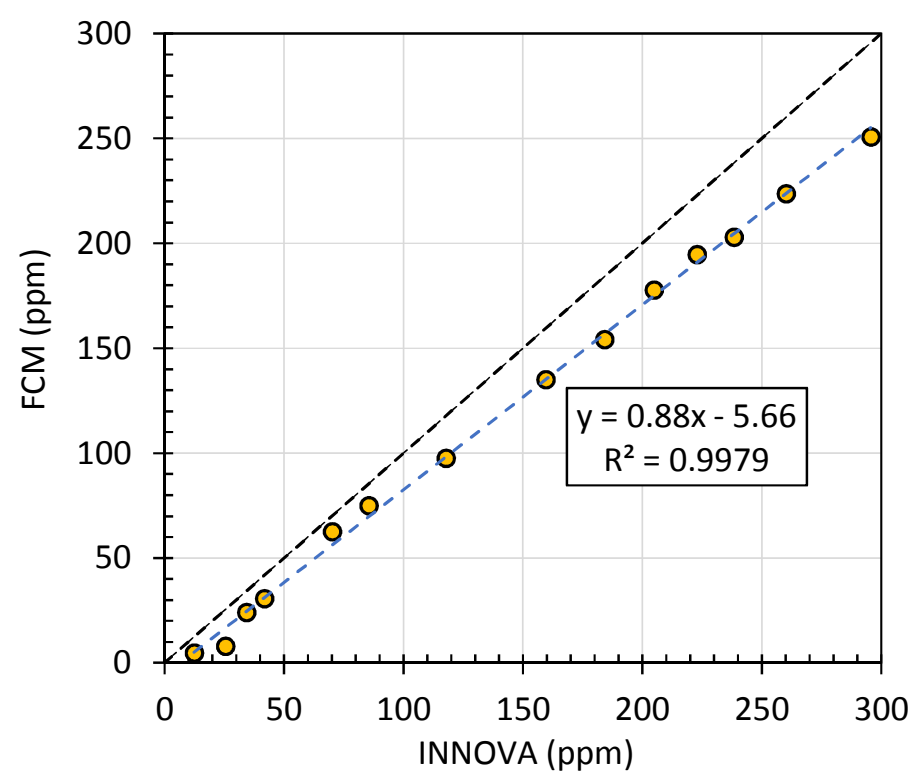

Figure 3 Cross-comparison of the slow (INNOVA) and the fast (FCM) methods at various levels of concentration under steady-state conditions.

A comparison of the two instruments was further made during a short $(5 \mathrm{~min})$ period (see Figure 4), when the separation distances between the two manikins were $0.35 \mathrm{~m}$ (a) and 1.0 $\mathrm{m}$ (b). As the sampling interval of the INNOVA (two channels used) was 80 s, only 4 samples were obtained during each 5 min period. For the FCM, however, 1200 samples were obtained. At the two separation distances, the average exposure indices calculated from the INNOVA results differ from those calculated from the FCM results by $85.4 \%$ and $53.1 \%$, respectively. It is therefore obvious that the 4 samples obtained by the INNOVA cannot indicate both the evolution of the exposure index over time and the time-averaged exposure index during this period of time. The limitation of the slow instrument to measure accurately is more significant at $\mathrm{D}=0.35 \mathrm{~m}$ than at $\mathrm{D}=1.0 \mathrm{~m}$, basically because the flow interaction in the breathing zone is stronger at $\mathrm{D}=0.35 \mathrm{~m}$ than it is at $\mathrm{D}=1.0 \mathrm{~m} \cdot{ }^{4}$ In general, the comparison made here suggests that fast concentration measurements using the FCM is a more reliable method for investigating dynamic airborne transmission during short-term events.

This article is protected by copyright. All rights reserved. 

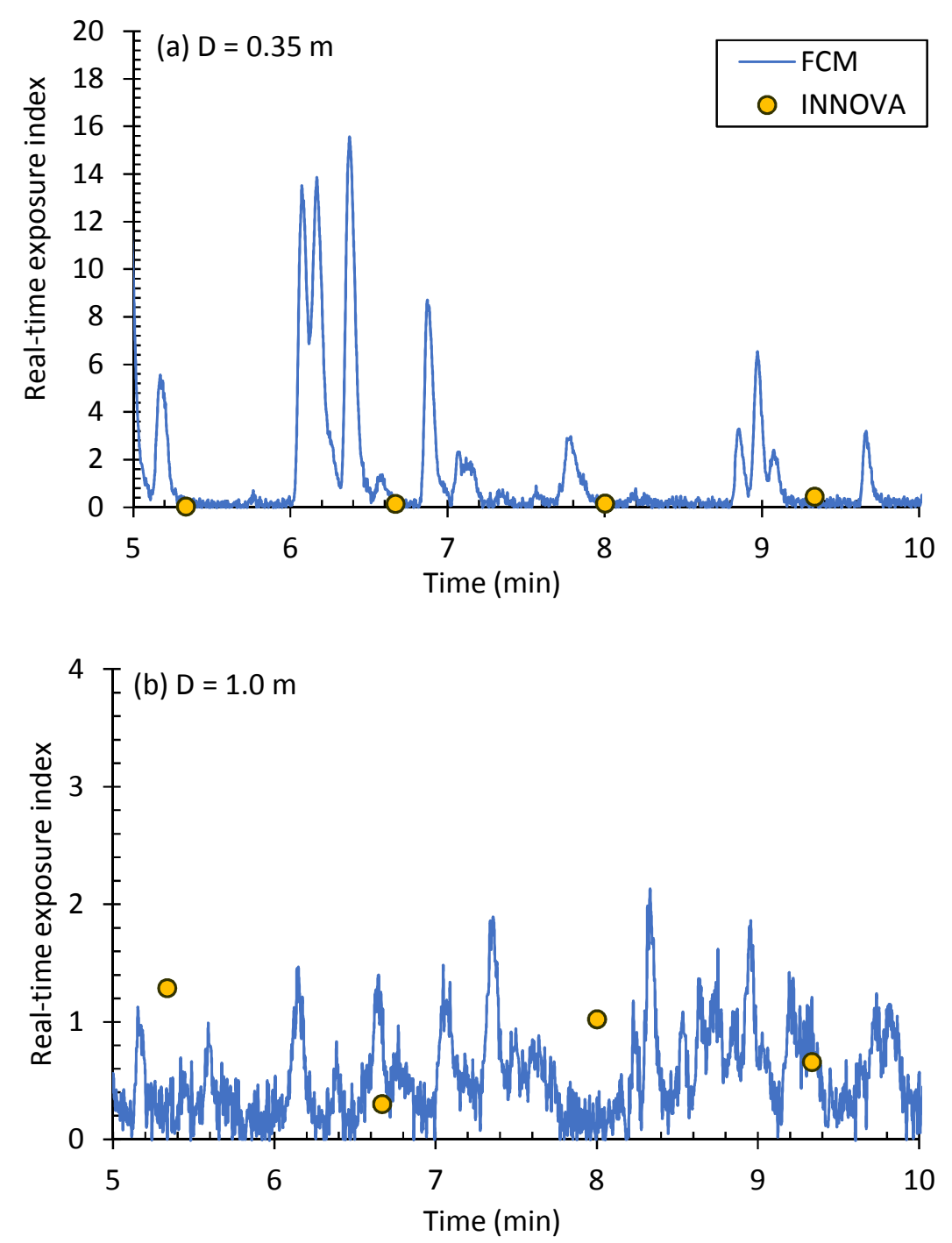

Figure 4 Comparison of the evolution of the real-time exposure index (see Section 3.2.2 for definition) given by the slow and the fast methods during a short (i.e., $5 \mathrm{~min}$ ) period of airborne transmission ( $\mathrm{SV}$, Positioning $\mathrm{A}, \mathrm{ACH}=2 \mathrm{~h}^{-1}$ ).

\subsection{Development of a dynamic evaluation method}

\subsubsection{Limitations of existing evaluation methods}

In order to evaluate dynamic airborne transmission, a suitable evaluation method is required. In the context of steady-state conditions, there are two widely used methods for evaluating the risk of cross-infection, namely intake fraction $(I F)^{34,35}$ and exposure index $\left(\varepsilon_{S}\right) .{ }^{6,9,10,13,15,18,21,22,36-42}$

This article is protected by copyright. All rights reserved. 
The intake fraction is defined as the proportion of pollutant mass exhaled from the infected person that is then inhaled by the exposed person, ${ }^{34,35}$ which can be written as:

$$
I F(t)=\frac{\int_{0}^{t_{i n}} C_{i n}(t) M_{i n} d t}{\int_{0}^{t_{e x}} C_{e x}(t) M_{e x} d t}
$$

where $C_{i n}$ is the inhaled concentration of the exposed person, $C_{e x}$ is the exhaled concentration of the infected person, $M_{\text {in }}$ and $M_{e x}$ are mass flow rates of inhaled flow of the exposed person and exhaled flow of the infected person, respectively, $C_{i n}(t)$ and $C_{e x}(t)$ are the inhaled concentration of the exposed person and the exhaled concentration of the infected person at time $t$, respectively, $t_{i n}$ and $t_{e x}$ are the exposure time of the exposed person and the respiratory time of the infected person, respectively.

During the present experiments, it was found that the $C_{e x}$ was extremely sensitive to the sampling location and dosing flow rate. On one hand, the sampling location might be changed slightly from case to case because of the change of experimental setup, although efforts were made to ensure the same location during all cases. However, owing to the large concentration gradient in front of the mouth, even a tiny change of the sampling location by, for example $0.001 \mathrm{~m}$, would result in a large difference in $C_{e x}$. On the other hand, the dosing flow rate of tracer gas could not be kept exactly the same in different cases. Even a small difference in dosing flow rate would cause a large difference in $C_{e x}$. The recorded $C_{e x}$ values in the present study varied by $\pm 15 \%$ between the different cases.

Unlike the intake fraction, the exposure index takes the concentration at the ventilation exhaust, instead of at the source person, as a normalization reference to indicate the risk of cross-infection of the exposed person, which is expressed as:

$$
\overline{\varepsilon_{S}(t)}=\frac{\overline{\left[C_{l n}(t)-C_{\text {supply }}(t)\right]}}{\overline{\left[C_{\text {exhaust }}(t)-C_{\text {supply }}(t)\right]}}
$$

where $C_{\text {supply }}$ and $C_{\text {exhaust }}$ are the pollutant concentration at the ventilation supply and exhaust, respectively; the overhead bar indicates averaging during the time period of $t$. In this study, the tracer gas $\left(\mathrm{N}_{2} \mathrm{O}\right)$ concentration in the ventilation supply ( $\left.C_{\text {supply }}\right)$ can be considered to be zero.

This article is protected by copyright. All rights reserved. 
During the present experiments, it was found that many spurious and extremely high values of $\overline{\varepsilon_{S}(t)}$ were obtained at the beginning of tracer gas dosing (i.e., at small $t$ ), which further increased the $\overline{\varepsilon_{s}(t)}$ values until the end of an event or cross-infection (i.e., at large $t$ ). The reason is that the concentration at the ventilation exhaust, $C_{\text {exhaust }}$, starts to increase at a later time than at the inhalation of the exposed manikin, which therefore results in extremely low concentrations at the exhaust at the beginning of dosing.

\subsubsection{New dynamic evaluation method}

In order to obtain a proper evaluation of dynamic airborne transmission, a new evaluation method was developed in this study. The new method utilizes the stability of the average concentration at the ventilation exhaust under steady-state conditions. It has the following expressions for evaluating both real-time risk of cross-infection at a specific moment and average risk of cross-infection during a specific time period (since the start of the event), respectively.

$$
\begin{aligned}
& \varepsilon_{d}(t)=\frac{C_{\text {in }}(t)}{\overline{C_{\text {exhaust-steady }}}} \\
& \overline{\varepsilon_{d}(t)}=\frac{\overline{C_{\text {ln }}(t)}}{\overline{C_{\text {exhaust-steady }}}}
\end{aligned}
$$

where $\varepsilon_{d}(t)$ and $\overline{\varepsilon_{d}(t)}$ are the real-time exposure index and the time-averaged exposure index, respectively; $\overline{C_{\text {exhaust-steady }}}$ is the average concentration at the ventilation exhaust under steady-state conditions. A proportional method was then proposed to calculate the standard deviations of the $C_{i n}(t)$ during a specific time period $t$, which is written as:

$$
\sigma_{d}(t)=\sigma_{\text {exhaust-steady }} \cdot \frac{\overline{C_{\text {ln }}(t)}}{\overline{C_{\text {exhaust-steady }}}}
$$

where $\sigma_{d}(t)$ and $\sigma_{\text {exhaust-steady }}$ are the standard deviations of the $C_{\text {in }}(t)$ during a specific time period $t$ and the standard deviation of the $C_{\text {exhaust-steady }}$ under steady-state conditions, respectively.

This article is protected by copyright. All rights reserved. 
For each case, there is only one value for the term $\overline{C_{\text {exhaust-steady }}}$. The advantages of using this term include first, avoiding the influence of the delayed building-up of concentration at the exhaust terminal and second, counteracting the intervention factors involved in the concentration measurements of $C_{i n}(t)$ through normalization. The disadvantage would be that, for each case, measurements under steady-state conditions must be conducted, even if the interest is only in the short-term events that end before the steadystate condition has been achieved. In addition, the new exposure indices are built upon the presumption that the tracer gas dosing is stable all the time during the whole process of a specific condition (see Table 1 for conditions).

\subsection{General dynamic characteristics of airborne transmission}

The general dynamic characteristics of airborne transmission are shown in Figure 5. It can be seen that the real-time exposure index is never a constant and fluctuates over time. For the cases shown in Figure 5(a), the time-averaged value of the real-time exposure index (and standard deviation) are 0.83 (and 1.66) and 0.78 (and 0.52) for $\mathrm{D}=0.35 \mathrm{~m}$ and $\mathrm{D}=1.0 \mathrm{~m}$, respectively. The observed fluctuations of $\varepsilon_{d}(t)$ are caused by the fluctuation of the tracer gas concentration in the air inhaled by the exposed manikin, which essentially resulted from the intermittent exhalation of tracer gas by the infected manikin as well as the instability and turbulence of the airflow, especially in the breathing zone. The fluctuation intensity is determined by factors that influence the level of the inhaled concentration, such as the separation distance between the two manikins.

This article is protected by copyright. All rights reserved. 

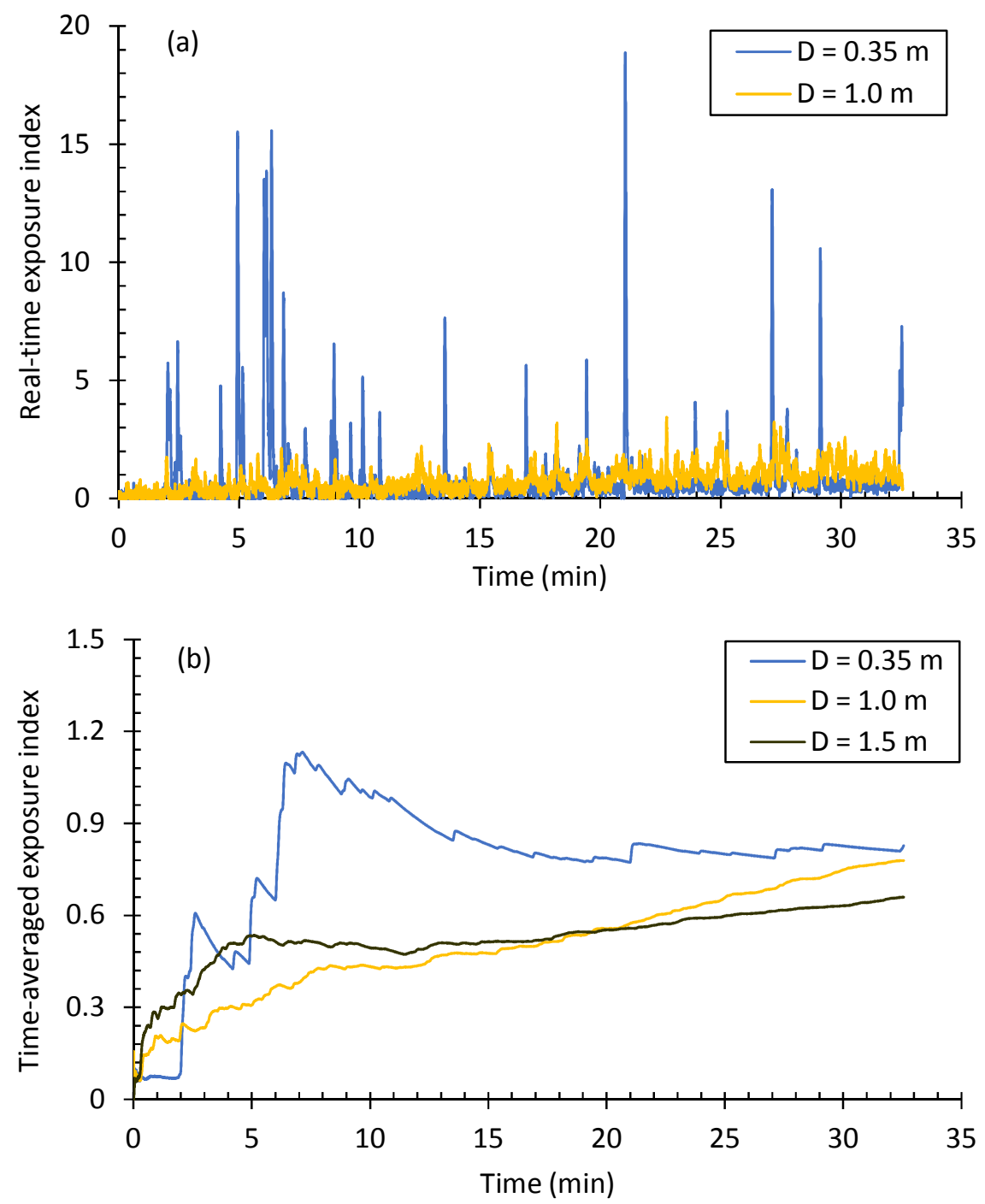

Figure 5 Evolution of real-time and time-averaged exposure index over time (SV, Positioning $\mathrm{A}, \mathrm{ACH}=2 \mathrm{~h}^{-1}$ ).

The fluctuating real-time exposure index results in a varying time-averaged exposure index over time, as shown in Figure 5 (b). Here two observations can be made. First, the time-averaged exposure index can vary substantially over time, especially when the separation distance is short (i.e., $0.35 \mathrm{~m}$ ). This is an important finding, as it implies that the time-averaged exposure index is dependent on the duration of an event. Second, the change of time-averaged exposure index over time at different separation distances follows different patterns. The time-averaged exposure index at a short separation distance does not 
necessarily always have a higher value than at a longer separation distance, which, again, depends on the duration of an event.

\subsection{Variation of time-averaged exposure index among repeated measurements}

The results presented in this paper were mostly obtained based on single sets of measurements. In order to evaluate the variation of time-averaged exposure index among repeated measurements under same conditions, this section presents the results and analysis of repeated measurements of a few cases (see Figure 6).

As shown in Figure 6 (a)-(b), the variations of time-averaged exposure index during shortterm events among three repeated measurements are considerable at $\mathrm{D}=0.35 \mathrm{~m}$, which become much moderate at $\mathrm{D}=1.0 \mathrm{~m}$. Such variations are closely related to the fluctuation intensity of real-time exposure index during a short-term event, as indicated by the standard deviations shown in Figure 6 (a)-(b). The large variations demonstrate the inherently random nature of time-averaged exposure index during short-term events (see detailed analysis in Section 4). For both cases at $\mathrm{D}=0.35 \mathrm{~m}$ and $\mathrm{D}=1.0 \mathrm{~m}$, the largest standard deviation in time-averaged exposure index among the three repetitions occurs during the 2 min event, and the standard deviation mostly decreases with the increase of the duration of an event (see Figure 6 (c)). These findings support that the results obtained from single sets of measurements can be very different from the averages of many repeated measurements.

With regard to the change of time-averaged exposure index with event duration, at $\mathrm{D}=$ $0.35 \mathrm{~m}$ (Figure $6(\mathrm{a})$ ), the three repetitions reveal that the time-averaged exposure index may not always increase with the increase of event duration; at $\mathrm{D}=1.0 \mathrm{~m}$ (Figure 6 (b)), the three repetitions show that the time-averaged exposure index increases with the increase of event duration. With regard to the change of time-averaged exposure index with separation distance (Figure $6(\mathrm{~d})$ ), the three repetitions reveal that the time-averaged exposure index may not 
always decrease with the increase of distance. Overall, these results support the use of single sets of measurements to demonstrate the different characteristics of airborne transmission during short-term events from those under steady-state conditions.
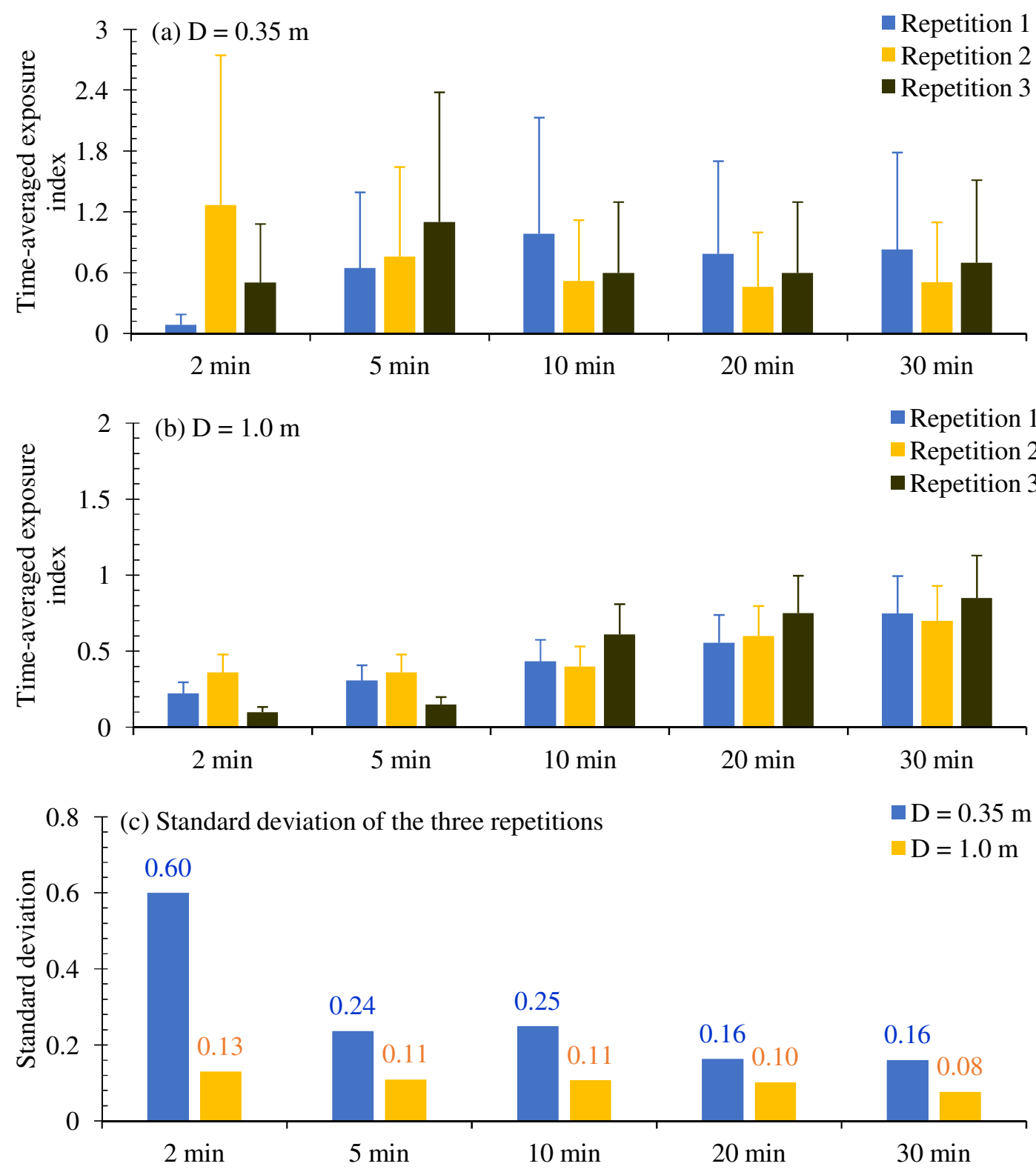

This article is protected by copyright. All rights reserved. 


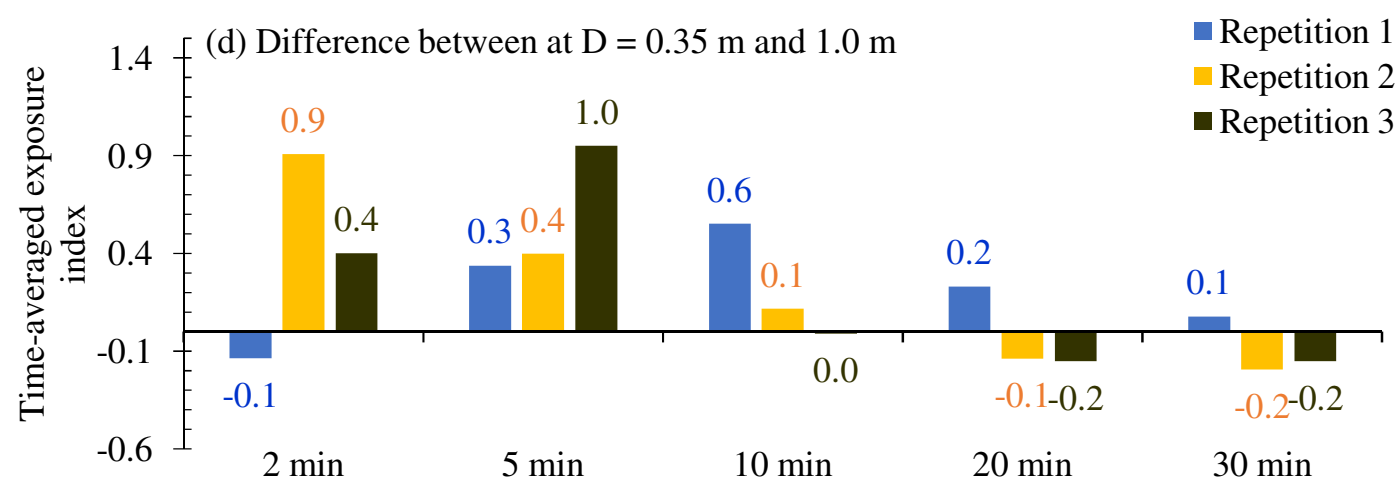

Figure 6 Variation of time-averaged exposure index during short-term events among repeated sets of measurements under the same condition ( $\mathrm{SV}$, Positioning $\mathrm{A}, \mathrm{ACH}=2 \mathrm{~h}^{-1}$ ); the sign of the numbers above or below the bars in (d) indicate the relative magnitude of the difference of time-averaged exposure index between those at $\mathrm{D}=0.35 \mathrm{~m}$ and $\mathrm{D}=1.0 \mathrm{~m}$, where positive means that the value at $\mathrm{D}=0.35 \mathrm{~m}$ is larger than at $\mathrm{D}=1.0 \mathrm{~m}$.

\subsection{Airborne transmission during short-term events}

\subsubsection{Influence of separation distance}

Figure 7 shows the influence of the separation distance on the time-averaged exposure index during various short-term events under SV. As the general trend of the influence of separation distance (and also positioning, in Section 3.5.2) is the same among the three air distribution methods, the results of MV and DV are not presented. The results under steadystate conditions are also plotted to facilitate the comparison. From this figure, four findings can be obtained. First, for most conditions (especially at $\mathrm{ACH}=6 \mathrm{~h}^{-1}$ ), the separation distance is still the dominant factor determining the risk of cross infection, which means that the timeaveraged exposure index mostly decreases with an increase in separation distance. Second, the time-averaged exposure index may not always decrease with an increase in the separation distance (this is supported by the repeated measurements presented in Section 3.4). At ACH =

This article is protected by copyright. All rights reserved. 
$2 \mathrm{~h}^{-1}$ (Figure 7(a)), the time-averaged exposure index increases with the separation distance during the first $2 \mathrm{~min}$; it first decreases and then increases with distance between the 5 th and 10th min; and it always decreases with distance during a 30 min event and in a steady-state condition. Third, the time-averaged exposure index may not always increase over time (this is supported by the repeated measurements presented in Section 3.4), especially under conditions with a short separation distance and a large ACH (Figure 7(b), D = 0.35 m), where the exposure index during a 20 -min short-term event is higher by up to $70 \%$ than in the steady-state condition. Fourth, increasing $\mathrm{ACH}$ results in higher exposure indices during short-term events at a distance of $0.35 \mathrm{~m}$, which must be attributed to the intensified dispersion of the exhaled tracer gas as well as the increased fluctuation and uncertainty of the exposed concentration.
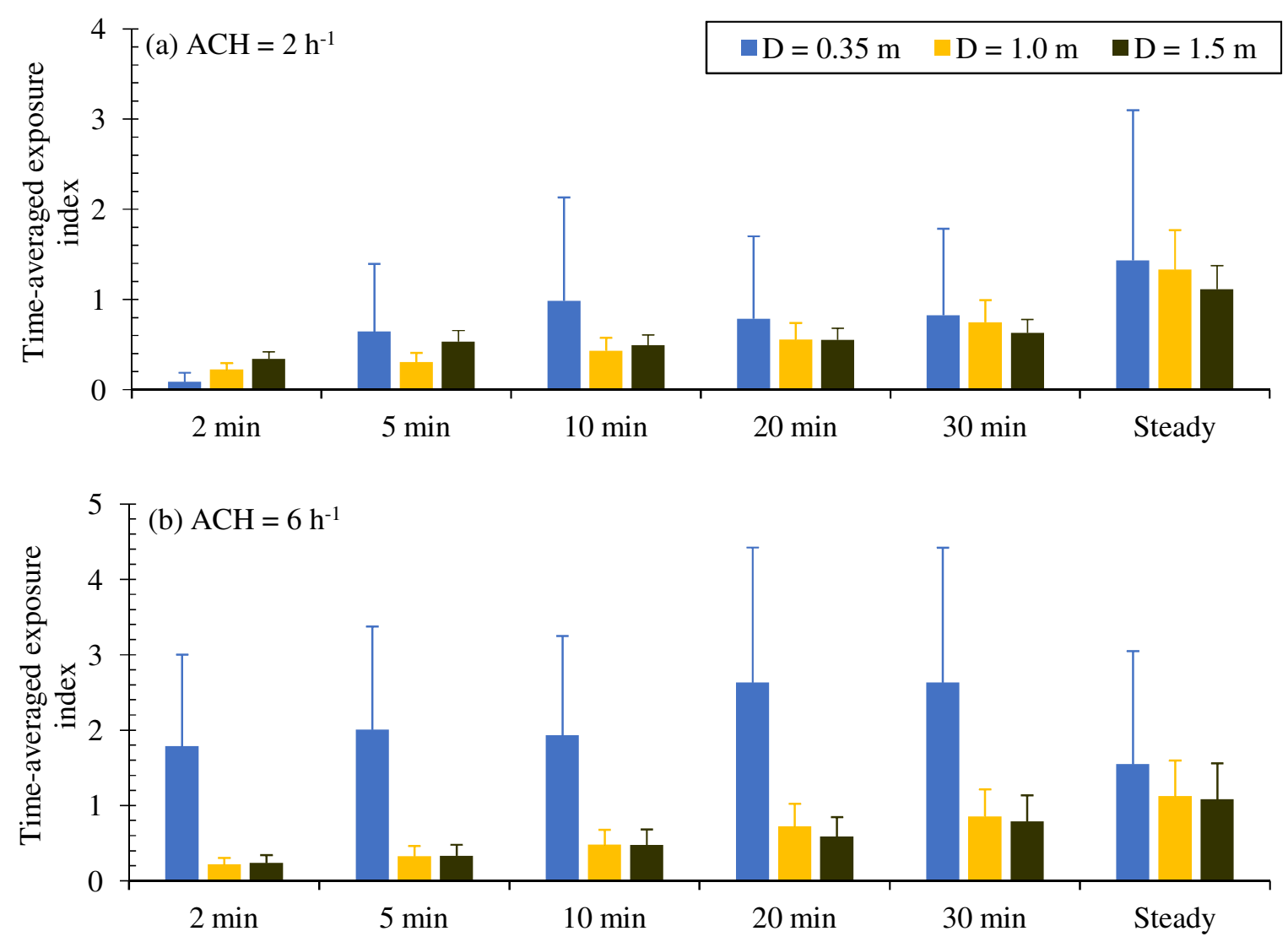

This article is protected by copyright. All rights reserved. 
Figure 7 Comparison of time-averaged exposure indices at different separation distances during various short-term events and under steady-state conditions (SV, Positioning A).

\subsubsection{Influence of positioning}

Figure 8 shows the influence of positioning on the time-averaged exposure index during various short-term events and under steady-state conditions. At ACH $=2 \mathrm{~h}^{-1}$, face-to-face positioning $(\mathrm{A})$ is riskier than face-to-back positioning $(\mathrm{C})$ both for short-term events and in the steady-state condition. However, the relative difference in time-averaged exposure index given by the two types of positioning depends largely on the duration of an event, which, for example, is $72.9 \%$ for 2 min and $30.4 \%$ for the steady-state condition. Previous studies ${ }^{10,14,16}$ have reported that, under steady-state conditions, face-to-face is the riskiest positioning and face-to-back is the safest. This study adds that the face-to-face positioning should be avoided even during short-term events. When $\mathrm{ACH}=6 \mathrm{~h}^{-1}$, the two types of positioning gave very similar exposure indices. The reason is that the strong intervention of the horizontal supply flow on the breathing zone helped to disperse the exhaled tracer gas into the room air so that direct exposure was largely reduced. The findings can also lead to the conclusion that $\mathrm{ACH}$ has equal or even larger influence than positioning on the risk of cross-infection.

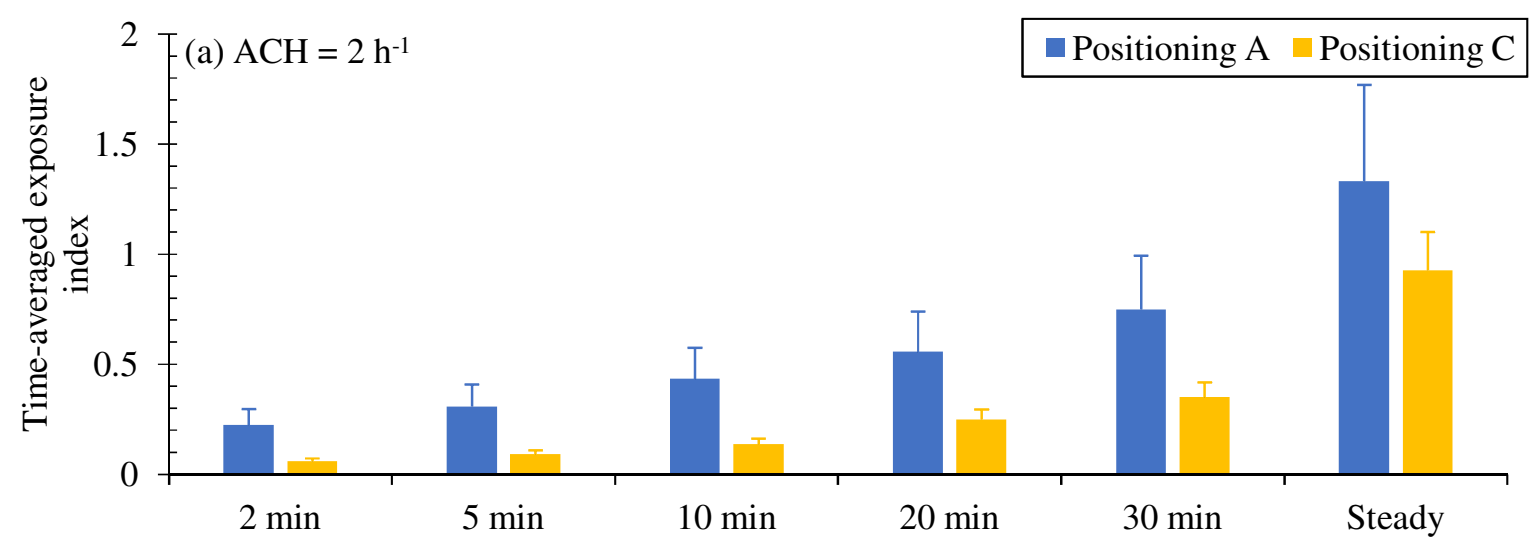

This article is protected by copyright. All rights reserved. 


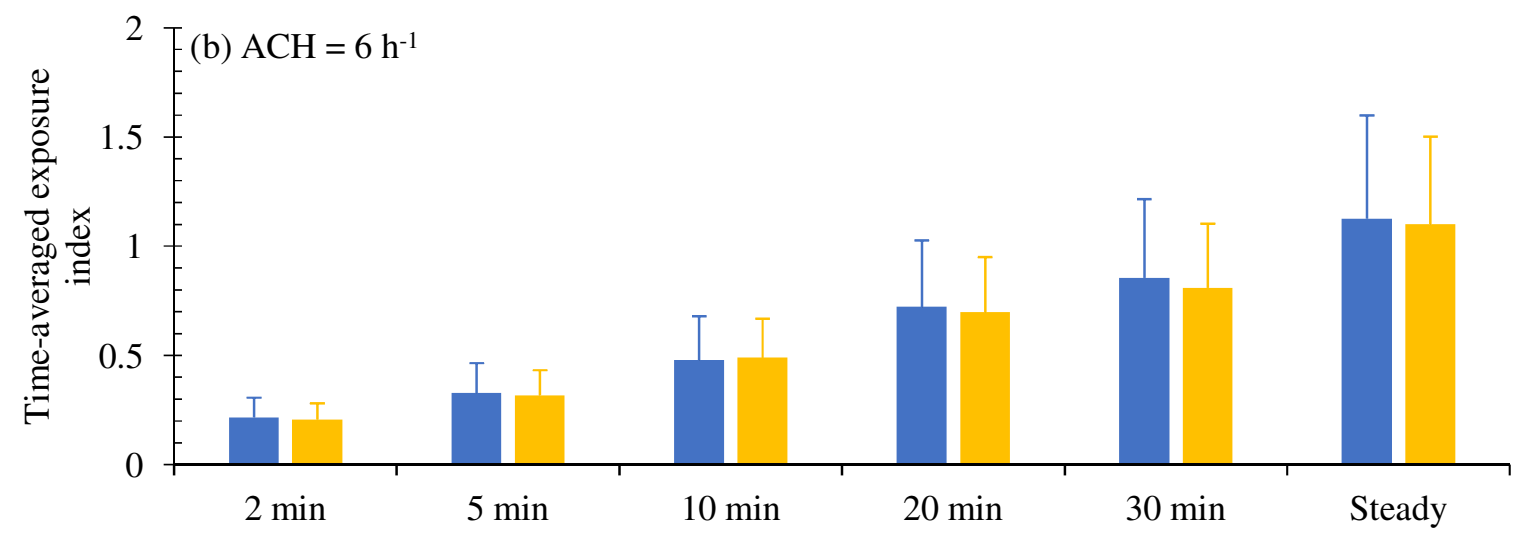

Figure 8 Comparison of time-averaged exposure indices at different positioning during various short-term events and under steady-state conditions $(\mathrm{SV}, \mathrm{D}=1.0 \mathrm{~m})$.

\subsubsection{Influence of air distribution methods}

Figure 9 shows the influence of air distribution on time-averaged exposure index during various short-term events and under steady-state conditions. The trend for either SV or MV to result in the highest average exposure indices and DV to result in the lowest was mostly the same for both short-term events and steady-state conditions. In addition, the relative differences in time-averaged exposure index given by the three air distributions during different short-term events and steady-state conditions are close to each other, with a relative deviation of less than $15 \%$ for most conditions. This suggests that the influence of air distribution is generally small, regardless of the duration of an event.

This article is protected by copyright. All rights reserved. 

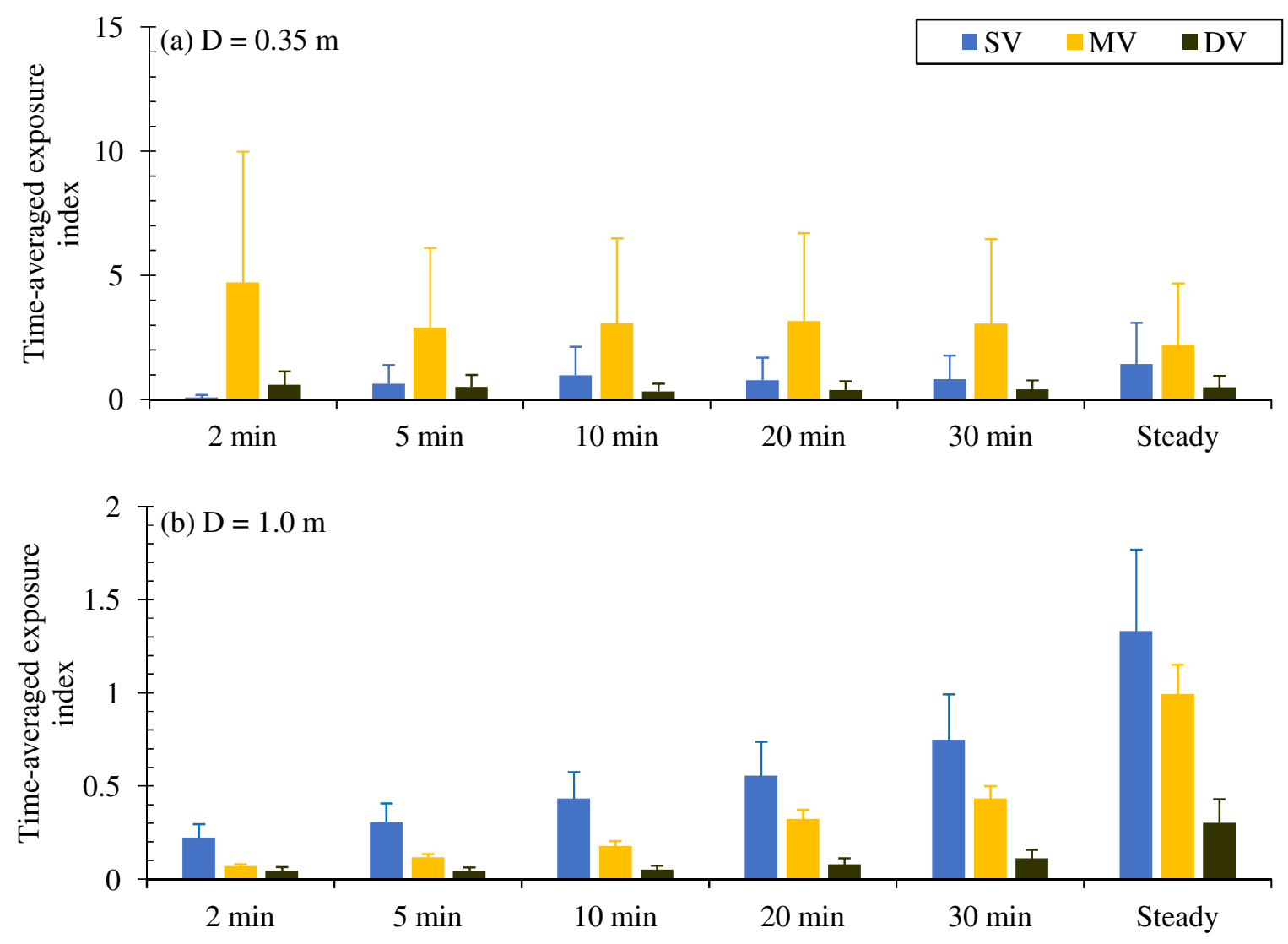

Figure 9 Comparison of time-averaged exposure indices under the three air distributions during various short-term events and under steady-state conditions (Positioning $\mathrm{A}, \mathrm{ACH}=2$ $\left.\mathrm{h}^{-1}\right)$.

\section{Discussion}

This study examined airborne transmission between room occupants during short-term events, focusing on its measurement, evaluation and characteristics. The findings are intended to contribute to improved understanding and control of airborne transmission indoors.

The comparison of the fast and slow measurements of tracer gas concentration during short-term events indicates clearly the limitations of slow measurements in investigating the dynamics of airborne transmission and the need for fast measurements. The sampling interval for slow measurements is much longer than the fluctuating timescales of the concentration in the breathing zone, so they cannot capture the detailed evolution of the exposure, and these details are important for the evaluation of short-term events. The reasons for the large and 
rapid fluctuation of the exposure concentration include two main aspects. One is the short timescale of tracer gas release, which took place only during the exhalation, i.e. during 2.5 seconds of each 6-seconds breathing cycle. The other is the strong flow interaction and thus highly varying concentration exposure that occurs in the breathing zone.

An analysis of two widely-used risk-evaluation methods (intake fraction and exposure index) reveals their limitations in evaluating dynamic airborne transmission and thus the need to develop a new evaluation method. The methods have been shown in many past studies to be suitable for evaluating airborne transmission under steady-state conditions. They are theoretically also suitable for dynamic conditions. However, as found in the present experimental study, the special aspects that make the two methods less applicable for dynamic conditions include first, the difficulty of making accurate and reliable measurements of the very variable temporal and spatial changes in the concentrations in the exhalation of the source manikin and second the spurious and extremely high exposure indices obtained at the beginning of each event.

The results of the present study show that larger fluctuations of real-time exposure index occur at shorter separation distances. The jet exhaled from relatively small mouth opening of the infected manikin expands, entrains and mixes with air from the surrounding before it is inhaled by the exposed manikin. The interaction of the exhaled jets, the convective boundary layers around manikins and the ventilation flow increases the flow turbulence at the breathing zone of the exposed manikin. At a short distance (e.g., $\mathrm{D}=0.35 \mathrm{~m})$, large fluctuations in concentration occur, because first the flow turbulence in the breathing zone of the exposed manikin is relatively strong and second the exhaled air from the infected manikin has not been much mixed with the surrounding air. At a long distance (e.g., $\mathrm{D}=1.0 \mathrm{~m}$ ), lower fluctuations of concentration occur, because first the flow turbulence in the breathing zone of 
the exposed manikin is relatively weak and second exhaled air from the infected manikin has been increasingly mixed with and diluted in the surrounding air.

The results of the present study show that the exposure index during short-term events may not always decrease with an increase in separation distance. It has been shown in previous studies $^{6,8,9,10,13}$ that under steady-state conditions the exposure risk always decreases with an increase in the separation distance. This general relationship between the exposure index and the separation distance has in fact been suggested as the basis for formulating control measures for short-range airborne transmission ${ }^{13}$. However, during short-term events, the present study found that the risk may even increase with an increase in separation distance, which is the opposite of what has been reported under steady-state conditions. Note that the short-term events investigated in the present study are under the condition with building-up background concentration. In this case, the background concentration is relatively low and non-uniform when compared to steady-state conditions. With a low and non-uniform background concentration, large stochastic fluctuations of concentration in the inhalation of the exposed person occur. The fluctuations are due to strong interaction of flows ${ }^{43}$. The exposure depends on the magnitudes of the random fluctuations during the period of a short-term event. As a result, the time-averaged exposure index may be larger for a longer separation distance (see Figure 5 for an example). Previous studies ${ }^{3}$ imply that the exposure index should always increase over time until it reaches a maximum, steady-state, level. On the contrary, the present study shows that the exposure index is not always higher during a longer period of exposure, basically because the exposed concentration is not constant and fluctuates considerably over time. In general, the differences between short-term events and the steady-state condition imply that control measures based on steady-state conditions are not necessarily effective for short-term events.

This article is protected by copyright. All rights reserved. 
The results of the present study show that the relative difference in exposure index given by face-to-face and face-to-back positioning is higher during short-term events than under steady-state conditions at $\mathrm{ACH}=2 \mathrm{~h}^{-1}$. The main difference between the two types of positioning lies in the direct exposure level, as the indoor background concentrations are more or less the same. The difference between short-term events and steady-state conditions should therefore be attributed to the fact that the background concentration during short-term events is less than it is under steady-state conditions. For two closely positioned persons, the proportion of exhaled droplet nuclei involved in direct exposure is quite small and most of them dissipate into the room and contribute to an elevated background concentration. The background concentration accumulates continuously from the start of dosing until it reaches a maximum level under steady-state conditions. In general, face-to-face positioning should always be avoided from the viewpoint of cross-infection. The difference between the two types of positioning is, however, not nearly as marked at $\mathrm{ACH}=6 \mathrm{~h}^{-1}$ (see Section 3.5.2).

Despite the aforementioned differences between the exposures resulting from short-term events and under steady-state conditions, the present study shows that the influence of air distribution is generally the same regardless of the duration of an event. To illustrate the reason, one experimental condition should be recalled, which is that the dosing of tracer gas starts after the airflow distribution reaches steady state. After steady-state conditions have been achieved, the influence of a specific air distribution system on the transport of droplet nuclei should be the same, regardless of the duration of an event, although turbulence would contribute to some dynamic uncertainties.

The findings of the present study may be used to formulate more specific control measures for airborne transmission during short-term events. An important implication of this study is that control measures aimed at reducing direct airborne transmission during shortterm events would be more effective than dilution ventilation. The reason is that dilution 
ventilation reduces the background concentration, but the background concentration during short-term events is certainly less than it is under steady-state conditions. An example of suitable control measures would be localized protection methods, such as personalized exhaust ventilation ${ }^{37}$ and breathing masks.

The following aspects should however be noted. First, this study is limited to tracer gas analysis. Second, this study is limited to using still manikins, whereas human movement ${ }^{44}$ is an important parameter influencing the risk of cross-infection. Third, the application of the newly developed evaluation methods relies on a stable dosing flow rate. Fourth, many repeated measurements under same conditions are required in order to analyse the statistics and variations of time-averaged exposure index during short-term events and to obtain quantitative results. Fifth, when evaluating the risk of cross-infection during short-term events, it must be borne in mind that exposure level is determined both by exposed concentration and exposed time period. Sixth, the results of the present study are limited to uncontrolled breathing phase of the two manikins. Finally, the short-term events investigated in this study are limited to the condition with building-up background concentration.

\section{Conclusions}

Single sets of measurements were conducted to reveal the general characteristics of airborne transmission during short-term events. Due to the random fluctuations during a short-term measurement period, the specific results obtained during single sets of measurements can be different from the averages of many repeated measurements. This study allows the following to be drawn.

- The newly developed indices, namely the real-time exposure index and the timeaveraged exposure index, show good performance in evaluating dynamic airborne transmission.

This article is protected by copyright. All rights reserved. 
○ The time-averaged exposure index during short-term events may not always decrease with an increase in separation distance, contrary to what has been reported under steadystate conditions.

○ The exposure index during short-term events changes over time and does not always increase with time. Taking SV as an example, exposure index during a short-term event may be up to $70 \%$ higher than in the steady-state condition.

○ At $\mathrm{ACH}=2 \mathrm{~h}^{-1}$, the relative difference in time-averaged exposure index given by the two types of positioning, face-to-face and face-to-back, decreases by up to $42.5 \%$ from shortterm events to steady-state conditions. This difference between the two types of positioning at $\mathrm{ACH}=6 \mathrm{~h}^{-1}$ is not nearly as marked, demonstrating the importance of $\mathrm{ACH}$.

○ Compared to other influential parameters investigated in this study, the air distribution system used has little influence on short term exposure, regardless of the duration of an event.

o In general, the exposure index is determined by the duration of the event, so the control measures formulated on the basis of observations made in steady-state conditions are not necessarily effective for short-term events.

$\circ$

\section{Acknowledgement}

The research leading to these results has received funding from the People Programme (Marie Curie Actions) of the European Union's Seventh Framework Programme (FP7/20072013) under REA grant agreement no. 609405 (COFUNDPostdocDTU). The first author, Dr. Zhengtao $\mathrm{Ai}$, is a recipient of a Marie Curie Fellowship. The authors would like to thank Prof. David Peter Wyon for his professional English language editing and technical suggestions. It is declared that all co-authors do not have a conflict of interest.

This article is protected by copyright. All rights reserved. 


\section{References}

1. Centers for Disease Control and Prevention (CDC). Guideline for Isolation Precautions: Preventing Transmission of Infectious Agents in Healthcare Settings, edited by Siegel JD, Rhinehart E, Jackson M, Chiarello L, The Healthcare Infection Control Practices Advisory Committee, Atlanta, GA: U.S. Department of Health and Human Services, 2007.

2. Centers for Disease Control and Prevention (CDC). Diseases \& Conditions. Atlanta, GA: U.S. Department of Health and Human Services available at: https://www.cdc.gov/DiseasesConditions, accessed on April 09, 2017.

3. Nielsen PV, Winther FV, Buus M, Thilageswaran, M. Contaminant flow in the microenvironment between people under different ventilation conditions. ASHRAE Trans. 2008; 114(2): 632-638.

4. Ai ZT, Melikov AK. Airborne spread of expiratory droplet nuclei between the occupants of indoor environments: A review. Indoor Air. 2018; 28(4): 500-524.

5. Melikov AK. Human body micro-environment: The benefits of controlling airflow interaction. Build Environ. 2015; 91: 70-77.

6. Villafruela JM, Olmedo I, San Jose JF. Influence of human breathing modes on airborne cross infection risk. Build Environ. 2016; 106: 340-351.

7. Nielsen PV, Li Y, Buus M, Winther FV. Risk of cross-infection in a hospital ward with downward ventilation. Build Environ. 2010; 45: 2008-2014.

8. Bolashikov ZD, Melikov AK, Kierat W, et al. Exposure of health care workers and occupants to coughed airborne pathogens in a double-bed hospital patient room with overhead mixing ventilation. HVAC\&R Res. 2012; 18(4): 602-615.

9. Olmedo I, Nielsen PV, Ruiz de Adana M, Jensen RL. The risk of airborne cross-infection in a room with vertical low-velocity ventilation. Indoor Air. 2013; 23: 62-73.

10. Olmedo I, Nielsen PV, Ruiz de Adana M, et al. Distribution of exhaled contaminants and personal exposure in a room using three different air distribution strategies. Indoor Air. 2012; 22: 64-76.

11. Bjørn E, Nielsen PV. Dispersal of exhaled air and personal exposure in displacement ventilated rooms. Indoor Air. 2002; 12: 147-164.

12. Melikov AK, Bolashikov ZD, Kostadinov K, et al. Exposure of health care workers and occupants to coughed air in a hospital room with displacement air distribution: impact of ventilation rate and distance from coughing patient. $10^{\text {th }}$ International Conference on Healthy Buildings, Brisbane, Australia, 2012.

13. Liu L, Li Y, Nielsen PV, et al. Short-range airborne transmission of expiratory droplets between two people. Indoor Air. 2016; 27(2): 452-462.

14. Pantelic J, Tham KW, Licina D. Effectiveness of a personalized ventilation system in reducing personal exposure against directly released simulated cough droplets. Indoor Air. 2015; 25: 683-693.

15. Melikov AK, Dzhartov V. Advanced air distribution for minimizing airborne crossinfection in aircraft cabins. HVAC\&R Res. 2013; 19: 926-933.

This article is protected by copyright. All rights reserved. 
16. Yang J, Sekhar C, Cheong DKW, Raphael B. A time-based analysis of the personalized exhaust system for airborne infection control in healthcare settings. Sci Technol Built En. 2015; 21: 172-178.

17. Bivolarova M, Ondracek J, Melikov A, Zdimal V. A comparison between tracer gas and aerosol particles distribution indoors: The impact of ventilation rate, interaction of airflows, and presence of objects. Indoor Air. 2017; 27: 1201-1212.

18. Pantelic J, Tham KW. Adequacy of air change rate as the sole indicator of an air distribution system's effectiveness to mitigate airborne infectious disease transmission caused by a cough release in the room with overhead mixing ventilation: a case study. HVAC\&R Res. 2013; 19: 947-961.

19. Pantelic J, Sze To GN, Tham KW, et al. Personalized ventilation as a control measure for airborne transmissible disease spread. J R Soc Interface. 2009; 6: S715-726.

20. Poon CKM, Lai ACK. An experimental stud quantifying pulmonary ventilation on inhalation of aerosol under steady and episodic emission. J Hazard Mater. 2011; 192: 1299-1306.

21. Sze To GN, Wan MP, Chao CYH, et al. Experimental study of dispersion and deposition of expiratory aerosols in aircraft cabins and impact on infectious disease transmission. Aerosol Sci Technol. 2009; 43: 466-485.

22. Cao G, Liu S, Boor BE, Novoselac A. Characterizing the dynamic interactions and exposure implications of a particle-laden cough jet with different room airflow regimes produced by low and high momentum jets. Aerosol Air Qual Res. 2015; 15: 1955-1966.

23. Fluent, ANSYS FLUENT 13.0 Theory Guide, turbulence. Canonsburg, PA: ANSYS Inc. 2010.

24. Yakhot V, Orszag SA. Renormalization group analysis of turbulence: 1 . Basic theory. $J$ Sci Comput. 1986; 1(1): 1-51.

25. Melikov AK. Breathing thermal manikins for indoor environment assessment: important characteristics and requirements. Eur J Appl Physiol. 2004; 92: 710-713.

26. Ai ZT, Mak CM. Large eddy simulation of wind-induced interunit dispersion around multistory buildings. Indoor Air. 2016; 26: 259-273.

27. Lin Z, Yao T, Chow TT, Fong KF, Chan LS. Performance evaluation and design guidelines for stratum ventilation. Build Environ 2011; 46: 2267-2279.

28. Melikov AK, Kaczmarczyk J. Measurement and prediction of indoor air quality using a breathing thermal manikin. Indoor Air. 2007; 17: 50-59.

29. Hoppe P. Temperatures of expired air under varying climatic conditions. Int J Biometeor. 1981; 25(2): 127-132.

30. Xu C, Nielsen PV, Liu L, et al. Human exhalation characterization with the aid of schlieren imaging technique. Build Environ. 2017; 112: 190-199.

31. Kierat W, Popiolek Z. Dynamic properties of fast gas concentration meter with nondispersive infrared detector. Measurement 95 (2017) 149-155.

32. Kierat W, Popiolek Z. Methods of the gas concentration sinusoidal and step changes generation for dynamic properties of gas concentration meters testing. Measurement 88 (2016) 131-136.

This article is protected by copyright. All rights reserved. 
33. Kierat W, Bivolarova M, Zavrl E, Popiolek Z, Melikov A. Accurate assessment of exposure using tracer gas measurements. Build Environ. 2018; 131: 163-173.

34. Nazaroff WW. Indoor particle dynamics. Indoor Air. 2004; 14: 175-183.

35. Bennett DH, McKone TE, Evans JS, et al. Defining intake fraction. Environ Sci Technol. 2002; 36(9): 206A-211A.

36. Qian H, Li Y. Removal of exhaled particles by ventilation and deposition in a multibed airborne infection isolation room. Indoor Air. 2010; 20: 284-297.

37. Bolashikov ZD, Barova M, Melikov AK. Wearable personal exhaust ventilation: improved IAQ and reduced exposure to air exhaled from a sick doctor. Sci Technol Built En. 2015; 21: 1117-1125.

38. Rim D, Novoselac A. Transport of particulate and gaseous pollutants in the vicinity of a human body. Build Environ. 2009; 44: 1840-1849.

39. Yang $\mathrm{C}$, Yang $\mathrm{X}$, Zhao B. Person to person droplets transmission characteristics in unidirectional ventilated protective isolation room: The impact of initial droplet size. Build Simul. 2016; 9: 597-606.

40. Zhu SW, Kato S, Yang JH. Study on transport characteristics of saliva droplets produced by coughing in a calm indoor environment. Build Environ. 2006; 41: 1691-1702.

41. Nielsen PV, Olmedo I, Ruiz de Adana M, et al. Airborne cross-infection risk between two people standing in surroundings with a vertical temperature gradient. $H V A C \& R$ Res. 2012; 18(4): 552-561.

42. Gao NP, Niu JL. Modeling particle dispersion and deposition in indoor environments. Atmos Environ. 2007; 41: 3862-3876.

43. Bivolarova MP, Kierat W, Zavrl E, Popiolek Z, Melikov AK. Effect of airflow interaction in the breathing zone on exposure to bio-effluents. Build Environ. 2017; 125: 216-226.

44. Cao SJ, Cen D, Zhang W, Feng Z. Study on the impacts of human walking on indoor particles dispersion using momentum theory method. Build Environ. 2017; 126: 195-206.

This article is protected by copyright. All rights reserved. 